"El hombre blanco habla de la mente, el cuerpo y el espíritu como si fueran separados. Son uno para nosotros. Nuestra vida entera es espiritual, desde el momento cuando nos levantamos hasta que nos vamos a la cama".

Curandero Yakima

\title{
ESPIRITUALIDAD: CONSIDERACIONES PARA LA PRÁCTICA DEL TRABAJO SOCIAL ${ }^{1}$
}

Noé Mojica Sánchez ${ }^{2}$

\section{Resumen}

El presente trabajo explora las conceptualizaciones y diferencias de lo que se entiende por religión y espiritualidad y su integración al trabajo social con el fin de considerar la totalidad del funcionamiento humano. El artículo describe los retos que tienen que enfrentar los/las profesionales en sus interacciones con la clientela para incluir la espiritualidad en sus ponderaciones. Se presta especial atención a las maneras en que las prácticas pueden resultar en detrimento de la clientela y se ofrecen preguntas guías para explorar el rol de la espiritualidad tanto en el sistema cliente como en el profesional del trabajo social.

Descriptores: religión, espiritualidad y trabajo social, diversidad, práctica profesional.

\footnotetext{
' Este trabajo tiene como base original una presentación del tema como invitación de la Profesora Rosa Figueroa Sánchez para el curso de Intervención Individual con Niños y Adolescentes.

${ }^{2}$ Trabajador Social, Children's Memorial Hospital, Chicago.
} 


\section{, Abstract}

The current work explores the conceptualizations and differences regarding religion and spirituality and their integration into social work to consider the holistic human functioning. The article describes the challenges that social workers have to face in their interactions with clients in order to include spirituality as part of their assessments. Special consideration is provided to the ways in which practices can be detrimental to clients and questions for analysis are provided to explore the role of spirituality with clients and social workers themselves.

Keywords: religion, spirituality and social work, diversity, professional practice

\section{Introducción}

Puerto Rico ha sido testigo de un rápido desarrollo de grupos religiosos y otras corrientes de pensamiento relacionados. Religiones que antes eran poco practicadas en el país, como el Islam y el Budismo, asumen un importante rol en la vida de algunos jóvenes puertorriqueños (Torres, 2006). Este conglomerado de prácticas y creencias vienen a formar parte de la realidad puertorriqueña junto a expresiones religiosas como la santería y el espiritismo, las cuales poseen una tradición más arraigada en algunos sectores populares. Por otro lado, hay un sector que no se identifica con las religiones establecidas y que incluso se define como ateo. Estas personas no asisten a la iglesia, ni les interesa la religión institucionalizada, pero aun así consideran vivir cierta forma de espiritualidad y enriquecimiento de su ser mediante su entusiasmo por la naturaleza, la vida misma y el deseo de aprender de lo vivido (Torres, 2006). Este tipo de vivencias en la población nos deja ver que Puerto Rico se dirige hacia una diversidad de creencias no tradicionales que se apartan de la religión institucionalizada que ha practicado la mayoría de la población. 
El presente trabajo invita a trabajadoras y trabajadores sociales a explorar la importancia que poseen estas concepciones sobre la espiritualidad, sus prácticas relacionadas y cómo sus clientes o clientas ven la vida a la luz de estas nociones y marcos de referencia. Conlleva, además, tener claramente establecido cuál ha de ser la perspectiva personal del profesional de trabajo social en cuanto a su propia espiritualidad y cómo esta afecta su interacción en el proceso de intervención. Partimos de la premisa de que todos y todas poseemos una forma de interpretar la vida y sus eventos, sea que le llamemos espiritualidad o utilicemos otros términos. Somos seres con capacidad para establecer relaciones y asociaciones simbólicas con nuestro entorno y sus experiencias, darle sentido e interpretación de acuerdo con esos simbolismos y significados para así construir la vida que deseamos. En la profesión de trabajo social se requiere estar al día en cuanto a cómo la espiritualidad se desarrolla en distintos contextos y la manera en que estos impactan la forma de ver e interpretar la vida de la clientela. De esta manera se facilita el comprender mejor a la persona en sus particularidades ya sea en lo social, psicológico y lo espiritual. De igual manera, nos ayuda a comprender a los individuos, grupos y comunidades en un continuo de interrelaciones.

Los trabajadores y trabajadoras sociales necesitan ejercer su rol desde una perspectiva que valore las experiencias diversas de su clientela, siendo fieles a los valores de la autodeterminación y el respeto a la diversidad, evitando a su vez el menospreciar las historias de vida y experiencias de sus clientes con relación a sus espiritualidades particulares. Esta orientación o postura del profesional de trabajo social está enmarcada en la visión de una espiritualidad que sea cónsona con las prácticas liberadoras, contrario a prácticas opresivas que van en detrimento de la salud integral de la clientela. Entendemos por prácticas opresivas a aquellas en las que el trabajador o trabajadora social impone sus criterios y juicios valorativos sobre la clientela y sus perspectivas, 
causando así un atropello a la capacidad de tomar decisiones y reflexionar desde su propio lugar social y espiritual.

\section{Espiritualidad y religión}

Las visiones tradicionales de la espiritualidad la asocian con la búsqueda de una deidad o Dios (Casas y Campos, 2003) manifestado en una gama de nombres como Krishna, Yahvé, Alá, Ser Supremo, entre otros. Al día de hoy no hay un consenso o definición universal. De acuerdo a Testerman (1997), la mayoría de los estudios de espiritualidad han sido desarrollados desde una definición ligada a lo sagrado o teísta. Moberg (2002) señala que tanto el practicante como la practicante poseen una gran variedad de orientaciones normativas y metas al momento de definir el concepto. El mismo autor critica el que se trate de aplicar estas interpretaciones como si fueran universales cuando lo cierto es que están condicionadas a criterios evaluativos de grupos particulares que establecen lo que es "espiritualidad". ¿Dónde, por ejemplo ubicamos a quienes practican una espiritualidad que niega la existencia de una deidad? Como alternativa, Kirkwood (1994) sugiere que la espiritualidad denota las aspiraciones existenciales más elevadas de los individuos y comunidades y los medios para alcanzar éstas. Dada la cantidad de formas de definir el concepto, podemos entonces hablar de espiritualidades en tanto que estas reflejan un sinnúmero de contextos y experiencias que varían ampliamente a tono con la subjetividad y experiencias particulares, entorno social y económico, entre otras variables.

Canda (2002) señala que el llamado movimiento de "trabajo social y espiritualidad" emerge en los Estados Unidos. Describe como los académicos y académicas de otros países se enfocan en la experiencia estadounidense para aprender de ella obviando el elitismo intelectual que condiciona y dicta lo que se debe estudiar. En este coloniaje intelectual se usan como referencias y modelos las definiciones establecidas por 
la academia estadounidense sobre lo que es espiritualidad y las pautas para su análisis y elaboración teórica.

La mayoría de las espiritualidades reconocen una conexión entre lo individual/colectivo con el resto del mundo y el universo. Demandan una fuerte sensibilidad a las necesidades de las demás personas: se requiere un marco holístico. Con esto nos referimos a la unión del todo, el cual es mayor que la suma de las partes y la importancia de la interdependencia de sus componentes. Este enfoque en la interrelación incorpora la justicia social y económica, los derechos humanos y la ecología sustentable. Para García Roca (2004) la vida sin vínculos es algo imposible. Por un lado existe el deseo de la vida independiente, más por otro existe la necesidad de una relación de convivencia duradera con otras personas. Chile y Simpson (2004) elaboran algunos puntos de este enfoque:

- Todo pensamiento y acción tienen consecuencias en las personas y el ambiente.

- La humanidad está unida a la tierra por lo que debemos promover lá justicia, unidad, empatía, compasión, y el altruismo en la vida diaria, actuando para y como parte de un todo.

La espiritualidad propone una sociedad solidaria, de redes de apoyo teniendo en mente que una gran parte de la humanidad no puede mantenerse en pie y no pueden estar activos o activas de acuerdo a los patrones estipulados por la economía de mercado. La palabra "espíritu" proviene del latín "spiritus" la cual significa "aire", "vida", o "valentía". Spiritus se deriva del término griego "pneuma" el cual se asocia con "aire", "aliento" o "soplo". También, se encuentra su equivalente en el idioma hebreo: "ruach", que significa "viento" o "aliento". Por lo tanto, espiritu es aquello que anima, que infunde aliento, que da vida, vigor, pasión o inspiración para funcionar (Baker, 2003). Con lo mencionado anteriormente deseamos distanciarnos de las nociones que limitan la espiritualidad al 
ámbito de lo personal o lo íntimo. Nuestra crítica al enfoque de la espiritualidad como algo limitado a la esfera individual es que es débil en cuanto a una visión y compromiso con la justicia social y los cambios macro estructurales. Se privilegia la dimensión horizontal (lo trascendental) y se minimiza su dimensión vertical (lo social) lo corpóreo; en el caso del cristianismo, se ha negado o reprimido en muchos momentos de la historia la sensualidad y la sexualidad como parte de esa vida en el cuerpo. Por otro lado, también debemos que estar concientes de que aunque muchas de las experiencias de carácter espiritual suelen darse en el contexto de la religión institucionalizada, muchas otras de igual manera se enmarcan fuera de lo que llamamos "religión".

Nuestra orientación en cuanto a la definición de religión reconoce los debates actuales y la polarización que se establece entre quienes afirman que religión y espiritualidad son términos intercambiables. Avilés Ruiz y Rivera (2003) señalan que la religión es el conjunto estructurado, organizado de creencias y prácticas espirituales compartido por una comunidad. Añaden las autoras que es una expresión de fe externa compuesta de códigos éticos y prácticas de adoración, rituales, dogmas y credos de una identidad o denominación. Para propósitos de este trabajo hablamos de religión cuando pensamos en la representación institucional, formal, doctrinal y en muchos casos autoritaria, de manejar los asuntos relacionados con lo divino o sagrado.

De acuerdo a algunas interpretaciones de la realidad, existe una dicotomía entre lo espiritual y las experiencias humanas. Se crea una polarización entre el mundo metafísico/ sobrenatural y el mundo material. Esta desconexión establece la base para una visión de mundo que puede ser altamente problemática y de la cual somos testigos cuando interactuamos con nuestra clientela. Se presentan con graves conflictos existenciales y de valores al no poder armonizar sus experiencias humanas con las doctrinas o creencias de carácter religioso que se les han inculcado. Ejemplos de esto pueden 
ser personas con una orientación homosexual que se sienten excluidas de su iglesia local porque su comportamiento e identidad son señalados como pecaminosos y abominables. Así también, podemos mencionar la joven universitaria que cohabita con su pareja pero se sienta a escuchar las predicas en su comunidad de fe en contra de la "convivencia" y las relaciones sexuales "antes del matrimonio" y el llamado de su pastor a una cruzada de ayuno y oración en contra de "la inmoralidad sexual de la juventud puertorriqueña". El trabajador o trabajadora social puede encontrarse con estos escenarios y sentir apatía de tratar los temas con sensibilidad y empatía ante los dilemas espirituales que atraviesan sus clientes o clientas.

\section{Resistencia en el trabajo social a hablar del tema}

Existe la idea entre profesionales del trabajo social de que el tema de la espiritualidad es uno prohibido en la relación profesional. Se argumenta que los asuntos que tienen que ver con Dios o aspectos de espiritualidad son incompatibles con la profesión. Una vez el cliente o la clienta hacen mención de alguna pregunta relacionada con su fe, sus creencias en cuanto a la salvación, lo que su iglesia le dice u otro asunto relacionado, se le refiere rápidamente a una persona con liderato religioso o a cargo de la consejería espiritual. Se falla en hacer una ponderación minuciosa de lo que le ocurre a la persona que busca ayuda y se le priva de una intervención inmediata que atienda su situación antes de hacer un referido. Por otro lado, existe un tipo de intervención que aparenta explorar la realidad espiritual del cliente pero que va dirigida a descartar implícita o explícitamente lo que esta persona piensa y su visión de mundo. Es aquí donde encontramos un gran riesgo de violentar la capacidad de autodeterminación del cliente cuando el trabajador o trabajadora social intenta "convencer" a su cliente de que sus ideas son "sin sentido", "arcaicas", "distorsionadas", "erróneas", "mitos", o "irrelevantes". 
Nos enfrentamos al reto de reconocer y entender cómo nuestras creencias y concepciones de la realidad entran en juego en nuestras relaciones con la clientela; y a responder de manera ética y competente ante la diversidad religiosa y espiritual con la que nos encontramos en nuestras comunidades y centros de práctica. Contrario a quienes critican al profesional que busca conocer más sobre asuntos de espiritualidad, la exhortación es a explorar, las diversas formas sobre cómo la clientela ve la vida, el significado que le otorgan a sus experiencias y cómo sus espiritualidades pueden convertirse en una fuente de apoyo en medio de circunstancias de crisis como la pérdida de un empleo, enfermedad, conflictos bélicos, muerte en la familia, divorcio, transiciones en el desarrollo y otros. Preguntas como: "¿por qué me ocurre esto a mí?”; “¿qué he hecho para merecerme esto?” y “¿será que me han hecho un trabajo?", tienen relevancia en la relación trabajador o trabajadora social y cliente. Waller (n.d.) plantea que se tiene que evitar el riesgo de subyugar las construcciones de la realidad elaboradas por la clientela a las interpretaciones "expertas" del profesional.

La solución no consiste en enviar a la clientela a una iglesia o a una persona con jerarquía religiosa, de quienes desconocemos sus posturas o acercamientos al tema. Es posible que el cliente o clienta rechace la religión institucionalizada y lo menos que desea hacer es recibir un referido a un lugar que ya conoce y del cual ha salido con heridas emocionales y sufrido grave marginación por causa de sus experiencias de vida o modo de pensar. Conlleva un ejercicio junto al cliente o clienta que conduzca a la búsqueda de soluciones por la misma persona y a comenzar en un proceso de apropiación de nuevas herramientas para vivir y hacerle frente a los retos con los que se encuentra. Por lo tanto, nos corresponde crear puentes entre el trabajo social y la espiritualidad.

Reconocemos la cantidad de preocupaciones que colegas han manifestado al abordar el tema de la espiritualidad. Hemos sido testigo de la gran cantidad de abuso sexual por parte de líderes espirituales, la forma atropellante de usar el poder, la discriminación hacia las minorías sexuales y los textos sagrados que se han utilizado para 
justificarla, el sectarismo, la presunción de poseer la verdad absoluta, los dogmas rígidos que no permiten cuestionamientos, el instigamiento del temor basado en la idea de un castigo eterno y prédicas de aniquilación del alma y la educación religiosa huérfana de pensamiento crítico, distan mucho del amor, la compasión, la justicia y la tolerancia que dicen proclamar estas personas con un aparente nivel de gran espiritualidad. McKernan (2005) nos presenta una serie de pautas para dirigir nuestra exploración crítica y sensible a la vez sobre las prácticas:

1. Un serio compromiso para hacer que las creencias sobre la espiritualidad respondan a los estándares empleados en la práctica competente del trabajo social, incluyendo la integridad investigativa.

2. Que toda creencia debe que estar abierta a ser retada cuando esta contradice los códigos de ética profesional del trabajo social.

3. Las creencias, rituales e interpretaciones, ya sean de una corriente espiritual o de investigación en trabajo social, se entienden mejor en términos tentativos. Esta actitud hacia las creencias mantiene al profesional de trabajo social abierto/a otras personas y a nuevas y diferentes ideas.

4. La espiritualidad de calidad nos exhorta a la disciplina y estilo de vida que apoya la apertura y la autenticidad en nuestros acercamientos. Esto puede verse en contraposición al dogmatismo y el cultismo (existentes tanto en trabajo social como en la espiritualidad).

5. Es apropiado preguntarle al trabajador o trabajadora social sobre su perspectiva espiritual como tan importante es preguntarle en cuanto a su base teórica al momento de iniciar la relación profesional o en la búsqueda inicial de servicios y referidos. 


\section{Contexto espiritual de la clientela}

Es crucial que el trabajador y trabajadora social tenga conocimiento de la diversidad de experiencias que posee la clientela y como se inserta en el proceso de intervención con estas. Esto conlleva una búsqueda y consulta con fuentes de información que asistan al profesional en un enriquecimiento de su conocimiento en el área de los estudios sobre la espiritualidad. ¿Cuál es el contexto en el que se vive la espiritualidad puertorriqueña? Una preocupación que deseamos expresar es la proliferación de doctrinas que condenan a la gente, en especial a aquellas personas que piensan diferente a lo llamado "ortodoxo". Esto es fuente de intolerancia, discriminación y de opresión. La persona que solicita servicios de trabajo social puede provenir de comunidades espirituales donde se someten a legalismos por parte de sus líderes y de la membresía de estos grupos. Es común recibir en la práctica a personas que han sido condenadas al "infierno" por su forma de vestir, su manera de interpretar la Biblia, cuestionar lo establecido, casarse con una persona de otra tradición religiosa, haberse mudado sin la debida aprobación y asistir a una actividad deportiva o de entretenimiento no aprobada por sus líderes religiosos. Trabajadoras y trabajadores sociales deben prestar atención a los siguientes aspectos en la intervención profesional con personas procedentes de este tipo de ambiente:

1. El cliente o clienta establece expectativas poco realistas de la vida y sus complejidades.

2. Negación de la realidad mediante mecanismos de espiritualización, intelectualización, y racionalización. Se ignoran las necesidades físicas, sicológicas; emocionales o sociales.

3. Vergüenza y sentimientos de culpa.

4. Cuestionamiento del proceso terapéutico y su efectividad al dudar sobre la capacidad del profesional 
de trabajo social. Pueden despertase dudas en cuanto a si es correcto acudir a un profesional de la conducta cuando esta persona no comparte las mismas tradiciones o creencias en torno a la espiritualidad o poseen distinta afiliación religiosa.

Las mismas comunidades religiosas establecen un lenguaje peyorativo para señalar y estigmatizar a quienes han roto con el orden establecido. Las personas transgresoras son estigmatizadas como "carnales", "pecadores", "apartados", "no creyentes", “impíos", "cizaña", "contaminadas", "inmaduros," entre otros nombres y adjetivos. Ciertos estigmas también abundan en la población general en torno a prácticas y creencias del espiritismo. Este puede tildarse de "brujería" o "asuntos del diablo" por quienes desconocen las prácticas y en su ignorancia crean nociones distorsionadas de quienes profesan las creencias.

Gotterer (2001) discute el ejemplo de una mujer puertorriqueña de 56 años. Para esta mujer, su vida está guiada por quien llama su "Protector" quien inicialmente se le reveló en sueños. Su Protector personifica su espiritualidad. Este le habla y en ocasiones toma su cuerpo y se ríe. Ella lo adora mediante el uso de una muñeca, a la cual viste y le ora. En ocasiones coloca flores, velas, perfume y canela ante la muñeca porque eso le agrada al Protector. Su espiritualidad también posee elementos del cristianismo ya que también le ora a la Virgen María cuando tiene alguna preocupación. Su Protector le indica eventos que ocurrirán en el futuro, aunque ella preferiría no saberlos, pues lo considera una gran responsabilidad. Sin embargo, lo considera como un don de Dios. La mujer indica que su madre también poseía las mismas capacidades para predecir eventos. Para esta mujer su rol es advertir a las personas, pero les corresponde a ellas cambiar. Relata que pensó que su pariente había enloquecido cuando le informó que tenía las mismas capacidades que ella. Luego terminó aceptando este "don" divino. Esta forma de expresar la espiritualidad como otras poco comunes pudieran ser calificadas por algunos como desórdenes mentales, si se desconoce el trasfondo cultural de la persona. Unas 21 expresiones con nexos culturales podrían ser etiquetadas como 
trastornos sicóticos por los estándares de la psiquiatría tradicional y podría enviar erróneamente a la persona "diagnosticada" a navegar por el sistema de salud mental (Gotterer, 2001).

Por otro lado, también existen historias de vida donde ocurre una reformulación de la espiritualidad como lo es el caso de la situación de un grupo de mujeres en la lucha contra la Marina de Estados Unidos en Vieques. En un estudio realizado por Rodríguez (2002), ésta encontró que uno de los momentos donde la investigadora tuvo que romper con viejos esquemas fue al escuchar a las mujeres hablar de su fe religiosa. La autora señala que estas ponían a su Dios por delante, pero era un Dios distinto al Dios patriarcal. Rodríguez (2002, p.9) añade:

Las entrevistadas reafirmaron su compromiso con su desarrollo personal como mujeres, con vencer los miedos y vencer el dolor que han experimentado. Reconocen, además, la importancia de impedir que su deseo de ayudar a crecer a los demás, y el afán de hacerlos(as) sentir bien, tenga como base su aniquilación como mujer. También reconocen que no pueden desatender sus propias necesidades como personas... Se esfuerzan por resolver esas situaciones difíciles sin tener que sacrificar su integridad personal o sus compromisos de lucha social.

Para Rodríguez (2002) la investigación y el proceso de entrevista fue una experiencia de crecimiento profundo, donde tuvo que reflexionar constantemente y comenzar a explorar los cambios que se han estado dando en algunas viequenses.

Contrario a las historias definidas como abusivas u opresivas por la clientela, también encontramos aquellas que resultan ser liberadoras y que infunden aliento, esperanza, solidaridad y la búsqueda de mayor profundidad en la vida espiritual de quienes la practican. En ese aspecto nos encontramos con clientes que han podido sacar provecho de su dimensión espiritual mediante la lectura, el ejercicio físico, la musicoterapia, meditación, aromaterapia, la pintura, el baile, Tai Chi, yoga y ejercicios de respiración, como complemento a su conexión con alguna comunidad religiosa o grupo de interés. 
Independientemente de la experiencia espiritual de la persona hay algunas preguntas que pueden ser útiles para poder comprender mejor el contexto de la persona y su forma de ver la vida a la luz de su espiritualidad. Algunas preguntas sugeridas por Northcut (2000) son:

1. ¿Qué experiencias negativas o positivas con la religión o la espiritualidad ha tenido usted en el pasado?

2. ¿Qué importancia tiene para usted hoy la religión o la espiritualidad?

3. ¿Cuáles son sus prácticas espirituales? ¿Qué actitudes tiene hacia éstas?

4. ¿Le ha sido beneficiosa su espiritualidad o religión cuando ha tenido que enfrentar eventos de tensión en su vida? ¿Hasta qué punto continua utilizando esos recursos espirituales hoy?

5. ¿Existe un ser supremo como parte de su espiritualidad? Si ese es el caso, ¿cómo percibe a ese ser? ¿Lo imagina con ira, amante, que castiga, compasivo/a, distante, desinteresado/a, desligado/a?

\section{Orientación espiritual del profesional de trabajo social}

Es importante considerar y ser sensibles a nuestros propios conceptos y nociones opresivas que traemos a nuestras interacciones con la clientela. Cuando el cliente o clienta y profesionales del trabajo social poseen diferentes orientaciones espirituales, su lenguaje y expectativas también pueden diferir en significado. Las palabras más sencillas se prestan para interpretaciones incorrectas. Ejemìplos de esto podemos notarlo en palabras como "pecado", "sagrado", "mundo", "sacrificio", "moral" (todos estas poseen una variedad de definiciones de acuerdo al trasfondo espiritual de la persona). Palabras como "salvación" pueden tener un significado alentador para unas personas y aterrador para otras (Waller, n.d.). 
Un instrumento útil para profesionales del trabajo social consiste en desarrollar su propio genograma espiritual. Como muchos trabajadores y trabajadoras sociales estamos bastante familiarizados con el genograma como representación de genealogías y su uso en el trabajo clínico. De igual manera, el genograma espiritual representa la herencia en el área espiritual que posee la persona. Como instrumento nos muestra las personas, lugares, e ideas que conforman nuestra identidad cultural. De acuerdo con Northcut (2000) luego de construir el genograma espiritual, se deben hacerse las siguientes preguntas:

1. ¿Quiénes han sido las personas más significativas y cuáles han sido los hechos más significativos en mi desarrollo espiritual?

2. ¿Cómo éstas han afectado mi crecimiento y desarrollo espiritual?

3. ¿Cómo han cambiando mis posturas en los pasados 5 años?

4. ¿Ha habido alguna experiencia particular que haya hecho huella en mí?

5. ¿Cuáles son las ideas espirituales, libros, autores, personas o eventos más importantes para mí en este momento?

Northcut (2000) también sugiere establecer una línea cronológica que detalle las experiencias de carácter espiritual y eventos significativos al igual que las presentes vivencias. Este ejercicio puede generar las siguientes preguntas:

1. ¿Cuánto tiempo llevo en un caminar/travesía de carácter espiritual?

2. ¿Surgió este caminar de un hecho espontáneo o de un esfuerzo deliberado? 
3. ¿Existen algunas lagunas en mi crecimiento espiritual o ha sido mi desarrollo uno consistente?

4. ¿Ha cambiado mi perspectiva espiritual o mi posición desde mi infancia? Si ese es el caso, ¿cómo lo ha hecho?

Mediante estos ejercicios el trabajador y trabajadora social puede descubrir en su persona actitudes cínicas, rigidez en su forma de pensar y falta de esperanza. Estas actitudes afectan negativamente sus vidas personales y la efectividad en su trabajo con la clientela. Se convierte en un imperativo ético el atender esta esfera dada la importancia que poseen estas actitudes y experiencias para moldear a el/la profesional del trabajo social. Se previene el actuar en detrimento personal o de las personas a quienes se sirve. Las perspectivas constructivistas nos señalan las dinámicas de poder enraizadas en las relaciones terapéuticas y como se elaboran los significados y sistemas de creencias tanto en la clientela como en profesionales del trabajo social. Se requiere tener claro cuales son nuestros valores y creencias, para así monitorear nuestra actuación y rechazar cuando intentemos imponer nuestras opiniones y puntos de vista sin base empírica o desde un marco de referencia elitista y privilegiado. El trabajador y la trabajadora social poseen creencias acerca de la condición humana, su naturaleza, el sufrimiento, la capacidad de las personas para cambiar y el proceso de sanidad. Estas creencias son el producto de las experiencias personales y la capacitación formal universitaria. Estas creencias a su vez no están ausentes de juicios valorativos sobre lo que el profesional del trabajo social considera como correcto, bueno, recomendable o permitido. Por lo tanto, la orientación teórica así como sus creencias seculares, religiosas, espirituales y los valores de la trabajadora y trabajador social, organizan la manera de interactuar con la clientela, cómo se interpretan sus dilemas, dónde vemos patología o cómo apreciamos la presencia o ausencia de fortalezas y recursos en la clientela para elaborar juntos/as un plan de acción (Haug, 1998). 
Northcut (2000), nos clarifica que otra de las áreas que es preciso vigilar es el escenario clínico y como la persona terapeuta puede ser presa de la contratransferencia. Por ejemplo, la persona terapeuta podría envidiar la experiencia religiosa de su cliente o clienta, esto en el caso que ésta disfrute de una espiritualidad robusta, energizante, alegre u optimista. La persona terapeuta, en un momento de vulnerabilidad, podría sentirse devaluada. Así también, las personas terapeutas devalúan las experiencias de la clientela cuando creen que estos/as últimos están siempre en la defensiva al hablar sobre sus creencias religiosas para tratar o interpretar un asunto. Por lo tanto, algunas personas terapeutas intentan corregir a su clientela "resistente" y sus posiciones mediante extensas discusiones filosóficas que carecen de valor terapéutico. Intentan así "convertir" a sus clientes a la forma que apoya el/ la terapeuta. Este tipo de contratransferencia puede ocurrir cuando el cliente o la cliente y la persona terapeuta están en extremos opuestos en las posturas, ya sean liberales o conservadores. Por otro lado, existe también un riesgo cuando tanto la persona terapeuta como la clientela poseen creencias similares. Se puede asumir que "yo sé a lo que te refieres". Se puede prestar para una relación ambigua de las fronteras entre el profesional y sus clientes cuando se establecen relaciones duales ya que ambas personas pertenecen a la misma corriente de espiritualidad o comunidad religiosa. Se pueden también establecer categorizaciones de que la clientela "que piensa como yo" tiene más madurez, sicológicamente hablando, y por lo tanto, mucho más saludables en su forma de vivir.

Proponemos entonces una serie de áreas que entendemos son primordiales para que el trabajador y trabajadora social demuestre competencia y dominio del tema de la espiritualidad:

1. Que pueda explicar la diferencia entre religión y espiritualidad, entendiendo a tono con su propia construcción y sensibilidad hacia la diversidad de opiniones al respecto. 
2. Que pueda describir las prácticas y creencias espirituales dentro de un contexto cultural.

3. Que pueda explorar su propia identidad, sus creencias espirituales y religiosas para así aumentar la sensibilidad, el entendimiento y la aceptación de diversos sistemas de creencias.

4. Que pueda identificar sus limitaciones en cuanto a su entendimiento de las expresiones religiosas o espirituales de la clientela y demuestre destrezas adecuadas para referir.

5. Que pueda ponderar la relevancia de las dimensiones religiosas y espirituales en los asuntos que trabaja con la clientela en su relación terapéutica.

6. Que pueda utilizar los conocimientos y creencias espirituales de el/la cliente para lograr las metas terapéuticas acomodándolas a las preferencias expresadas por su cliente.

\section{Trabajo interdisciplinario}

Dada la complejidad del funcionamiento humano y la apertura de nuestra profesión al trabajo colaborativo, nos corresponde ponderar las situaciones que conllevan el involucramiento de personas participantes en beneficio del sistema cliente. En el escenario de hospital nos encontramos con el apoyo de departamentos de capellanía, los cuales pueden conectar con recursos en la comunidad que desconocemos como rabinos, centros de meditación, librerías, líderes laicos, lugares de consejería espiritual y otros. No debemos limitarnos a solo consultar a quienes tradicionalmente son las personas con el peritaje sancionado por la academia, sino también reconocer el valor que clientes le adscriben a curanderos o curanderas, santeros o santeras, guías espirituales, personas ancianas, y otras, quienes vienen a formar parte de la red de apoyo para la clientela. 
Les corresponde a los trabajadores y trabajadoras sociales crear conciencia en medio de sus escenarios de práctica sobre la importancia de evaluar a la persona en sus esferas sociales, culturales, biológicas, sicológicas y espirituales. Muchos estudios en el campo de la medicina señalan que la mayoría de los/las pacientes tienen una vida espiritual y consideran su salud espiritual como la física con igual importancia. Según Mueller, Plevak y Rummans (2001), la mayoría de estudios en el área de la medicina y la espiritualidad indican que las personas con algún tipo de participación en la vida de una comunidad religiosa o que poseen una vida espiritual están relacionadas con mejores resultados en su salud, incluyendo mayor longevidad, mecanismos para lidiar con las situaciones que generan tensión y calidad de vida (aun durante el proceso de muerte). Además, estos autores apuntan a que los/las sujetos que cultivan su dimensión espiritual o religiosa poseen un menor índice de ansiedad, depresión y suicidio.

En la esfera gubernamental, somos responsables de abogar por políticas públicas que tengan en consideración a grupos excluidos, en especial a aquellos que sufren marginación por su orientación sexual o género. Es crucial que llevemos nuestra voz para combatir ideas estereotipadas que persiguen dar la impresión al pueblo de que las personas que pertenecen a minorías sexuales carecen de "valores" o "moral". Grande es la labor que tienen las comunidades de base y sus organizaciones para refutar y contrarrestar los mensajes que señalan que estas personas carecen de espiritualidad. La lucha desgraciadamente, ha sido muchas veces denunciando y confrontando a instituciones religiosas que han perpetuado un mensaje en su contra al describir la identidad de las personas homosexuales, lesbianas, bisexuales, transgénero como personas que no son bienvenidas a la mesa. La trabajadora y trabajador social deben trabajar en solidaridad con esta comunidad que ha sufrido tanto discrimen históricamente. Tiene que ser una práctica que eduque en cuanto a la tolerancia, la diversidad y el respeto a la dignidad humana, todos estos muy ligados a la espiritualidad y a los valores del trabajo social. 
No podemos dejar a un lado tampoco el grito de la gente pobre del mundo, pero en especial de quienes viven en nuestra Isla y que sufren día a día el azote de políticas que les hacen más pobres y que no les permiten acceso a las mismas oportunidades que las clases privilegiadas. Es un grito ante el rampante individualismo y la cultura del consumo que reduce el ser humano a una mercancía y a transacciones con valor monetario. Es imposible dejar a un lado el tema de la pobreza cuando quienes la sufren son la mayoría del país. No solamente pobreza material, sino también de espíritu por las constantes practicas abusivas de las fuerzas de control social, la discriminación de las instituciones y la exclusión del mercado de bienes y laboral. Entre muchas personas como pastores y pastoras, rabinos, imanes, capellanes y capellanas, líderes laicos y laicas, psicólogos y psicólogas, miembros de la comunidad médica, profesionales jurídicos, educadores y educadoras, miembros de iglesias, y aquellas personas que no asisten a ninguna, necesitamos unidad de entusiasmo y motivación para cambiar las realidades que mantienen la frustración, la derrota y la falta de esperanza. Mientras no haya justicia social para todas las personas, el trabajo será inconcluso y la espiritualidad será reducida a una comodidad practicada en recintos apartados de la realidad de la gente que sufre y que ansía día a día que dicha realidad sea transformada.

\section{Espiritualidad y educación en trabajo social}

Es nuestro propósito abogar por la inclusión de temas sobre espiritualidad en la educación en trabajo social. Existe literatura que señala la necesidad de tratar el tema de una manera más abierta y activa en las escuelas de trabajo social. Un grupo de estudiantes de la Escuela Graduada de Trabajo Social de la Universidad de Puerto Rico participó en un programa de intercambio en los Estados Unidos, en el que tuvieron la oportunidad de escuchar sobre el tema de la espiritualidad. Para este grupo de estudiantes la experiencia resultó muy positiva y alentadora en cuanto a exponerse a un 
tema que no era discutido en sus cursos. Barreto Cortez (2002, p.71) recoge parte de los testimonios cuando una de las estudiantes señala:

Pude distinguir objetivamente la diferencia entre espiritualidad y religiosidad. Reflexioné sobre mi posición ante la iglesia con toda su estructura y mi relación con Dios. Disfruté mucho esta charla porque me permitió tener un espacio para profundizar en mi espiritualidad, aspecto esencial en mi vida.

Otra de las estudiantes presentes también compartió su opinión de la siguiente manera y lo presentamos a modo de conclusión:

Creo que es un paso en nuestra profesión en cuanto a hacer ver que el ser humano es mucho más que sus problemas y sus interpretaciones de su realidad, que es mucho más que roles que desempeñar, que es mucho más que emociones sino que en nosotros existen otras dimensiones más profundas que conforman nuestro existir.

\section{Referencias}

Avilés Ruiz, Z. \& Rivera L. (2003, junio). La importancia de la espiritualidad en la profesión de trabajo social. Ponencia presentada en la Tercera Conferencia de Trabajo Social Forense en la Universidad Interamericana de Hato Rey, Puerto Rico.

Baker, D. C. (2003). Studies of the Inner Life. Quality of Life Research, 12 (Suppl. 1), 51-57.

Barreto Cortez, E. (2002). Experiencias de un intercambio: La educación en Trabajo Social a través de Programas de Intercambio. Análisis, 3(1), 61-76.

Canda, E. R. (2002). A World Wide View of Spirituality and Social Work: Reflections from the USA Experience and 
Suggestions for Internationalization. Currents: New Scholarship in Human Services, 1(1), Retrieved from University of Calgary Web site http://fsu.ucalgary.ca/ currents_prod_v1/articles/canda_v1_n1.htm

Chile, L. \& Simpson, G. (2004). Spirituality and Community Development: Exploring the Link Between the individual and the Collective. Community Development Journal, 39 (4), 318331.

Gotterer, R. (2001). The Spiritual Dimension in Clinical Social Work Practice: A client Perspective. Families in Society, 82(2), 187193.

Hang, I.E. (1998). Including a Spiritual Dimension in Family Therapy: Ethical Considerations. Contemporary Family Therapy, 20 (2), 181-194.

McKernan, M. (2005). Exploring the Spiritual Dimension of Social Work. Critical Social Work, 6(2). Retrieved from http:// www.criticalsocialwork.com/units/socialwork/critical.nsf

Moberg, D.O. (2002). Assessing and Measuring Spirituality: Confronting Dilemmas of Universal and Particular Evaluative Criteria. Journal of Adult Development, 9(1), 47-60.

Mueller, P.S., Plevak, D.J. \& Rummans, T. (2001). Religious Involvement, Spirituality and Medicine: Implications for Clinical Practice. Mayo Clinical Proceedings, 76, 1225-1235.

Northcut, T.B. (2000). Constructing a Place for Religion and Spirituality in Psychodynamic Practice. Clinical Social Work Practice, 28(2), 155-169.

Purcell, B.C. (1998). Spiritual Abuse. The American Journal of Hospice \& Palliative Care, 15(4), 227-231. 
Rodríguez, J. (2002, abril). Voces de mujeres viequenses en su lucha por la paz: dejando atrás las jerarquías de dominación y abrazando la solidaridad. Ponencia presentada en el Congreso Universitario de Investigación y Proyectos sobre Vieques en el Anf. Rafael Cordero de la Facultad de Educación, Universidad de Puerto Rico, Recinto de Río Piedras.

Torres Torres, J. (2006, abril 9). Predican con la acción los jóvenes. El Nuevo Día, Retrieved from http://www.endi.com/2006/04/ 09/ElPais

Waller, M. (n.d.). The Spiritual Dimension of Assessing Human Functioning. Retrieved April 9, 2006, from Arizona State University Web site: http://www.public.asu.edu 